\title{
Design and Experimental Study of Centrifugal Compressor in Fuel Cell Vehicle
}

\author{
Wenguang LI*, Guosheng FENG** \\ *Shijiazhuang Tiedao University, 050043 Shijiazhuang, China, E-mail: nicky12@126.com (Corresponding author) \\ **Shijiazhuang Tiedao University, 050043 Shijiazhuang, China, E-mail:fgs2005@126.com \\ crossref http://dx.doi.org/10.5755/j02.mech.28301
}

\section{Introduction}

With the deepening of research on pure electric vehicles (EV), hybrid electric vehicles (HEV), fuel cell vehicles (FCEV) around the world, FCEV are considered to be very likely to replace ordinary fuel vehicles and become the main choice for future. It provides a solution that can meet the environmental regulations and can reduce carbon emissions. The stack uses oxygen in the air and hydrogen in the fuel tank to generate electrical energy. Water vapour is the only by-product of the reaction. It has the advantages of high energy conversion rate, environmental friendliness, low operating temperature, and is suitable for more frequent startups and continuously travel longer distances than battery electric vehicles. In addition, hydrogen is a clean and efficient energy source and one of the most abundant in the universe. It can be obtained by electrolysis of water and byproducts of various chemical production processes. In addition, it can be quickly filled and easily stored in FCEV fuel tanks.

The fuel cell system is composed of a fuel cell stack, an air treatment system, a fuel treatment system and a thermal management system. The air compressor is one of the key components of the system. It is important for the entire system in terms of efficiency, noise, vibration and harshness. It is the only component with high rotation speed in FCEV, which consumes the maximum parasitic power of the system. It needs high power and high speed to increase the system air pressure. It is essential to develop a compact, lightweight and efficient air compressor.

For fuel cell systems, there are usually centrifugal, screw and roots compressors. Compared with other types of compressors, centrifugal compressors have the advantages of compactness and high efficiency. The efficiency is continuously improved, the weight and size are reduced accordingly, and there is no problem of friction and wear, and the life is long, especially suitable for vehicle use. At present, there have been studies on the application of centrifugal compressors in FCEV, and the aerodynamic performance and $\mathrm{NVH}$ performance of centrifugal compressors have been discussed. With the application of gas foil bearings in compressors, the rotation speed of the compressor has been greatly improved, and the efficiency can be improved in the range of low flow and high pressure ratio. In particular, the gas foil bearings do not require oil lubrication, thereby avoiding the failure of fuel cell proton exchange membrane caused by oil pollution.

In fuel cell vehicle systems, the power density and efficiency requirements of air compressors are gradually increasing, and centrifugal compressors with high operating speed and direct electric drive are increasingly replacing volumetric and gear driven compressors. Combining a permanent magnet motor with a radial inflow turbine, the air compressor of this motor direct drive structure is more efficient. When using gas foil bearings, the whole machine structure is smaller, quieter, and requires less maintenance, and maximum efficiency can be achieved in a small space.

Honeywell has developed a high-speed centrifugal air compressor with a speed of $110,000 \mathrm{rpm}$, a maximum mass flow rate of $100 \mathrm{~g} / \mathrm{s}$, pressure ratio of 3.2, and a weight of $8.2 \mathrm{~kg}$ [1]. MiTi has developed a12 kw, $120000 \mathrm{rpm}$ centrifugal air compressor with gas dynamic pressure foil bearing, and carried out theoretical analysis and experimental research on rotor system dynamics and gas foil bearings [2]. Hyundai developed a third-generation centrifugal air compressor for on-board fuel cells based on gas foil bearings. Compared with the first-generation air compressor, its power has increased from $8 \mathrm{~kW}$ to $10 \mathrm{~kW}$, and its overall weight is $71 \%$ of the first-generation, and the volume is only $60 \%$ of the first generation [3]. Honda's first-generation Lysholm air compressor was relatively noisy and required the installation of a silencer or soundproof cover, resulting in an increase in its volume and weight. In order to overcome this shortcoming, Honda developed a two-stage centrifugal compressor [4]. The third-generation centrifugal air compressor developed by the Liebherr uses gas dynamic pressure bearings and permanent magnet synchronous motor drive technology. The maximum mass flow rate is $90-$ $110 \mathrm{~g} / \mathrm{s}$, the maximum pressure ratio is $2-3$, and the overall efficiency reaches $60 \%$. In fuel cell vehicles, high-speed centrifugal compressors have gradually become a trend.

In order to achieve the rated speed of the impeller and meet the requirements for compressed air, volume, and weight, the speed of the air compressor drive motor cannot be too low, so it is essential to develop high-speed motors, and high-current, high-frequency drive technology is also critical. Ultra-high-speed motors have the advantages of high efficiency, compactness, and light weight. They are widely used in high-speed systems. By increasing their speed, the system can be made smaller and lighter at the same power level, so high-speed motors are widely used in the field of vehicle engineering that requires a compact and light weight structure. In [5], a permanent magnet synchronous motor with a rated speed of $120,000 \mathrm{rpm}$ and a rated power of $15 \mathrm{~kW}$ was studied to meet the requirements of stator core loss and rotor eddy current loss. At the same time, the rotor structural stability and critical speed were evaluated. In document [6], a three-phase switched reluctance motor (SRM) is used to drive an air compressor in a fuel cell vehicle system. The maximum speed of the compressor is $140,000 \mathrm{rpm}$, the corresponding air mass flow rate is $25 \mathrm{~g} / \mathrm{s}$, and the air pressure ratio is 2 , which can be applied at $25 \mathrm{~kW}$ in the fuel 
cell system, the main problems of using SRM in automotive applications are: the need for external position sensors for control, the need to reduce noise and vibration, and the efficiency needs to be improved. BorgWarner has developed an air compressor for turbochargers [7]. It uses a $12 \mathrm{~kW}$ permanent magnet synchronous motor with a rated speed of $120,000 \mathrm{rpm}$ which provides additional boost at low engine speeds. At $86000 \mathrm{rpm}$, the system input power is $720 \mathrm{~W}$, greatly increasing the speed of the compressor, while reducing the volume and weight, especially suitable for smaller engine compartments. In addition, there are high-speed motors with speeds up to $200,000 \mathrm{rpm}$ in turbochargers and electric superchargers. The detailed performance of induction motors of $10 \mathrm{~kW}$ and $75000 \mathrm{rpm}$ is described in [8].

Considering the speed and application environment of the air compressor, the performance of the bearing is very strict. Conventional rolling bearings need to work in extreme conditions, the power loss will be large, and external lubrication and filtration are required. The system also puts forward higher requirements to prevent leakage and pollution of the fuel cell system. Surface self-acting dynamic pressure bearings solve the shortcomings of liquid lubricated bearings, use gas for lubrication, have lower power loss, have a longer service life in commercial applications, and provide key technologies for the development of oilfree air compressors. This article discusses the application of gas foil bearings in the preliminary design of air compressors and provides data for such bearings.

The air compressor is the core component of the fuel cell system. It is driven by a high-speed motor, the impeller is used to boost the filtered air and supply it to the fuel cell reactor, hydrogen reacts with oxygen in compressed air in an electrochemical reactor, and chemical energy is converted into electrical energy to provide power to the drive motor. Due to the special requirements of fuel cell vehicles, the following requirements are imposed on the air compressor: sufficient pressure and flow to optimize the efficiency of the fuel cell system; high-speed motor drive to ensure that the compressor can provide gas to the fuel cell system in advance source; no oil in compressed air to avoid fuel cell proton exchange membrane failure; low noise, low vibration, high reliability, stable start-stop performance, maintainability and long service life [9].

A technical scheme of gas foil bearing centrifugal air compressor with air as the medium was presented, and a preliminary discussion on the feasibility of its application in the fuel cell system of automobile was made. Because the research and development of centrifugal air compressor involves many technical fields, such as high-speed permanent magnet synchronous motor and its drive control technology, impeller design, etc. In this paper, the compressor structure, rotor system dynamics and gas foil bearing are analysed and discussed.

\section{Structural design}

The air compressor is mainly composed of an impeller, rotor components, gas foil bearings, a stator, and a housing. Due to the use of gas foil bearings, it satisfies the high-speed, oil-free use environment, and has good loadcarrying capacity, impact resistance, and stability.

In the scheme of this paper, the air compressor is driven by a high-speed permanent magnet motor, and the rotor is supported by gas foil bearings. The main design parameters are as follows: pressure ratio 1.2-2.3, mass flow $0.02-0.08 \mathrm{~kg} / \mathrm{s}$, rated speed 80,000 rpm, maximum speed $100,000 \mathrm{rpm}$, rated power $10 \mathrm{~kW}$, with reasonable surge margin. The motor includes a rotor assembly and a stator assembly, which are located between two radial bearings, as shown in Fig. 1. This arrangement can improve dynamic performance, and the rotor is a solid permanent magnet with high rigidity.

Due to the high speed, in order to reduce the size and improve its dynamic characteristics, the motor is located between two gas foil journal bearings, the impeller and gas foil thrust bearings are located at the front and rear of the rotor respectively. The large impeller is located at the front and compresses the air, the small impeller is located at the rear end and sucks the filtered air and introduces it into the interior to achieve the cooling of the bearings and the motor.

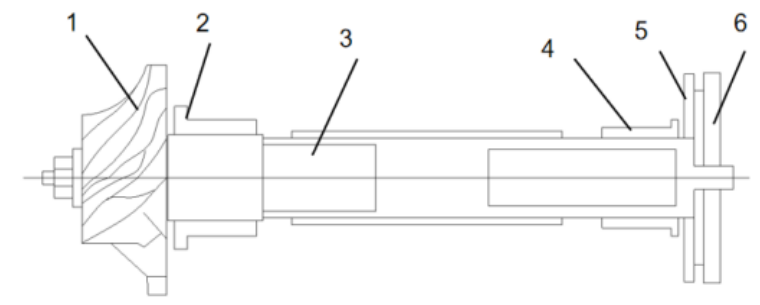

Fig. 1 Schematic diagram of the combined rotor structure: 1-Centrifugal impeller; 2-Left gas foil journal bearing; 3-Rotor components; 4-Right gas foil journal bearing; 5-Gas foil thrust bearing I; 6-Gas foil thrust bearing II

According to the requirements of the hydrogen fuel cell system, when the outlet pressure is $0.23 \mathrm{MPa}$, the cost of the fuel cell is lower and the efficiency is higher. The design speed of the centrifugal compressor is $100,000 \mathrm{rpm}$, and the outlet pressure at the rated speed is $0.23 \mathrm{MPa}$. According to the relevant research on the fuel cell, the actual air mass flow required by the fuel cell stack can be calculated by Eq. (1), and the calculated data can be substituted into:

$$
\left.\begin{array}{l}
Q_{m}=52.4 \mathrm{~g} / \mathrm{s}, \\
Q_{m}=3.57 \times 10^{-4} \times \lambda \times \frac{P_{\varepsilon}}{v_{c}},
\end{array}\right\}
$$

where: $\lambda$ is the stoichiometric ratio of the fuel cell stack, and the value is $2.2 ; P_{\varepsilon}$ is the output power of the fuel cell stack. Currently, the power of the commonly used fuel cell passenger car is $40 \mathrm{~kW}$, and $v_{c}$ is the unit voltage of the fuel cell stack, the value is $0.63 \mathrm{~V}$.

The gas foil bearing is used as the support, considering the air consumption of the gas bearing and the leakage of the compressor, the design flow rate of the compressor is $60 \mathrm{~g} / \mathrm{s}$, the design pressure ratio is 2.3 , and the design parameters are shown in the Table 1.

Gas foil journal bearing is mainly composed of shell, wave foil and flat foil. Under the action of aerodynamic pressure, the elastic support structure composed of wave foil and flat foil spontaneously deforms. The bearing clearance is formed by the elastic deformation of the foil. Compared with the rigid bearing, the gas bearing produces a larger minimum film thickness and a lower maximum atmospheric film pressure in operation [10]. The reduction of 
the maximum atmospheric film pressure can reduce the stress on the bearing surface and the maximum temperature so as to change the working conditions of the bearing and make the bearing work normally at high temperature, low temperature and high speed [11]. The sectional structure of the bearing is shown in Fig. 2.

Table 1

Air compressor design parameters

\begin{tabular}{|c|c|}
\hline Parameter & Value \\
\hline Bearing style & Gas foil bearing \\
\hline Inlet temperature & $295 \mathrm{~K}$ \\
\hline Inlet pressure & $101.32 \mathrm{kPa}$ \\
\hline Air mass flow & $60 \mathrm{~g} / \mathrm{s}$ \\
\hline Maximum pressure ratio & 2.3 \\
\hline Maximum speed & $100000 \mathrm{rpm}$ \\
\hline Quality & $14.5 \mathrm{~kg}$ \\
\hline Rated power & $10 \mathrm{~kW}$ \\
\hline
\end{tabular}

One end of the wave foil and flat foil is fixed on the bearing housing together, and the other end is in a free state. During the working process, the rotor rotates from the free end to the fixed end [12]. The surface of the flat foil is a working surface, and the surface of the rotor and the bearing is chrome-plated, which can reduce the dry friction between the rotor and the flat foil during the start-stop process and prolong the service life. In the stationary state, the rotor and the flat foil are closely attached together, as the rotor speed increases, due to the gas viscosity and wedge effect, a gas film pressure is formed between the rotor and the flat foil to support the rotor [13].

The empirical formula for the bearing capacity of gas foil journal bearing is:

$$
W_{B}=\Lambda\left(L_{B} \times D_{B i}\right)\left(D_{B i} \times \omega\right),
$$

where: $W_{B}$ is bearing load capacity; $\Lambda$ is bearing load factor; $L_{B}$ is the axial length of the bearing; $D_{B i}$ is bearing inner diameter; $\omega$ is working speed.

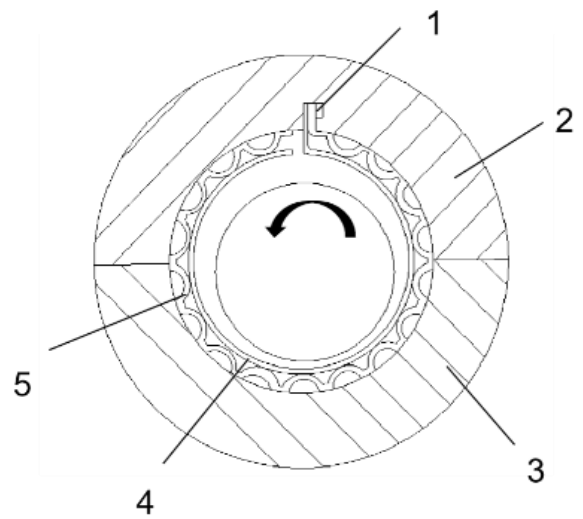

Fig. 2 Gas foil journal bearing structure: 1 - Fixed pin; 2- Upper tile; 3- Lower tile; 4-Flat foil; 5- Wave foil

Table 2

Geometrical parameters of gas foil journal bearing

\begin{tabular}{|c|c|c|c|}
\hline Bearing & $L_{B}, \mathrm{~mm}$ & $D_{B i}, \mathrm{~mm}$ & $D_{B 0}, \mathrm{~mm}$ \\
\hline Left & 26 & 28 & 36 \\
\hline Right & 32 & 28 & 36 \\
\hline
\end{tabular}

Gas foil thrust bearing uses the compression effect of the wedge-shaped gas film between the top foil and the thrust disk to generate axial bearing capacity [14]. In order to ensure the stability of the bearing, a stable and reliable wedge-shaped compressed gas film is required. The manufacturing precision of the support wave foil is high enough, and at the same time, the gas film thickness distribution shape of the inlet section is required to have a good compression effect.

Gas foil thrust bearing mainly includes bottom plate, support wave foil, top foil and gasket, a round bottom plate is set below, and multiple fan-shaped top foil is fixed above the bottom plate, the supporting wave foil is assembled between the bottom plate and the top foil, the thickness of the top foil in this design is $0.5 \mathrm{~mm}-1 \mathrm{~mm}$, pre-tightening assembly between the supporting wave foil and the top foil, the deformation of the supporting wave foil is 0.01 $0.02 \mathrm{~mm}$, as shown in Fig. 3. A wear-resistant coating is provided on the inner side wall of the top foil, and the coating is a molybdenum disulphide layer or a polytetrafluoroethylene coating.
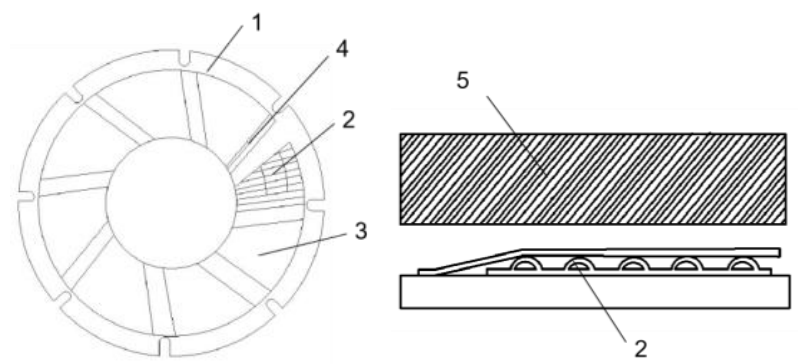

Fig. 3 Schematic diagram of gas foil thrust bearing: 1-Bottom plate; 2-Support wave foil ;3-Top foil; 4-Gasket; 5-Thrust disk

In the design, the method of increasing the thickness of the top foil is used. It reduces the accuracy requirements of the support wave foil [15]. At the same time, it solves the problem of foil deformation in the entrance section of the top layer, the thickness and shape of the gas film at the inlet section are basically unchanged, and the bearing capacity of the bearing is improved. Because the top foil and wave foil are pre-tightened, the bearing damping is increased, and the running stability of the bearing is improved.

The design of the bearing focuses on the parameters such as the inner and outer diameters, the working speed and the nominal clearance, because their influence on the bearing capacity of is relatively large, and the bearing capacity usually decreases rapidly with the increase of the nominal clearance. According to the empirical formula, its bearing capacity will increase as the bearing size becomes larger, and as the working speed increases [16]. The nominal clearance value is a relatively vague concept for gas foil thrust bearing, but it has a very large impact on the performance of the bearing. The preset nominal clearance value is $5 \mu \mathrm{m}$, and then the nominal clearance value is gradually increased, and finally the bearing load can be obtained the relationship between bearing capacity and nominal clearance, Fig. 4, a shows the relationship between the bearing capacity and the nominal clearance at a working speed of $20,000 \mathrm{rpm}$, Fig. 4, b is the change of the bearing capacity of the gas foil thrust bearing with the speed when the nominal clearance is preset to $5 \mu \mathrm{m}$. 


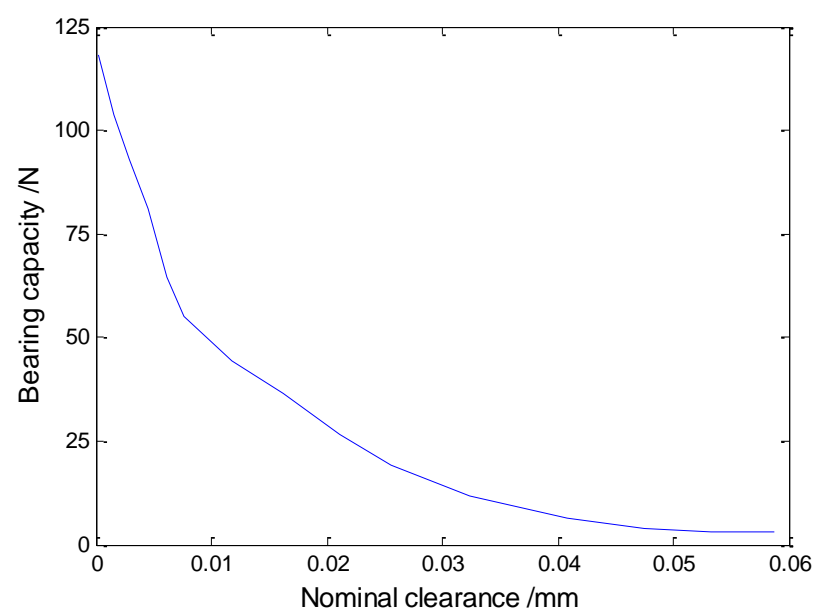

a) Relationship of bearing capacity-nominal clearance

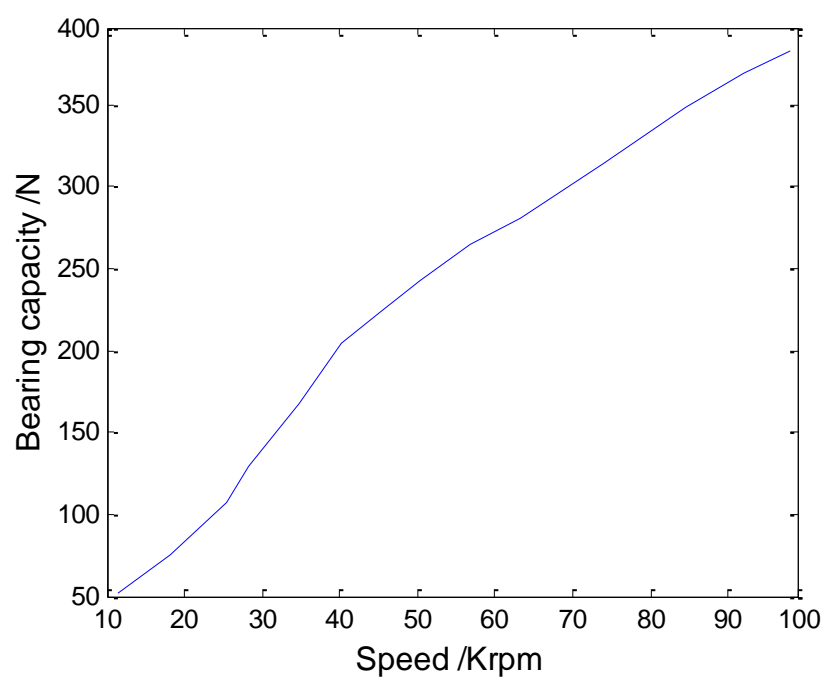

b) Relationship of bearing capacity-speed

Fig. 4 Gas foil thrust bearing capacity

\section{Electromagnetic design of permanent magnet syn- chronous motor}

The motor requires a wide speed range (0$100,000 \mathrm{rpm}$ ), and considering the characteristics of surface-mounted PMSM that are difficult to expand the speed with weak magnetic field, there must be many compromises in design, such as low electromagnetic utilization coefficient, power factor and efficiency. The purpose of this design is to propose a balanced compromise scheme to meet the following requirements: the rated efficiency is not less than $85 \%$; the rated power is $10 \mathrm{~kW}$ in the range of 20,000 to $100,000 \mathrm{rpm}$; the rated voltage is limited to $500 \mathrm{~V}$ (effective value); the eddy current loss of rotor is as low as possible.

In order to ensure the mechanical strength, rotor dynamics, electromagnetic performance and other requirements of the rotor, the motor adopts solid rotor instead of lamination; the air gap magnetic density of the conventional motor is generally controlled at about $1 \mathrm{~T}$, but the rotating speed of the motor is as high as 100,000 rpm, and the air gap magnetic density should be as low as possible to control the stator iron consumption; in order to reduce the circumferential stress difference as much as possible, and improve the torque density, the pole coverage of the type magnetic steel is set as 1 ; the selection of the shape of the stator lamination is mainly to reduce the iron consumption while reducing the outer diameter as much as possible, and to leave enough space for the winding at the same time; in order to make full use of the voltage [17], the number of turns of the winding should be selected so that the voltage limit is reached near $80000 \mathrm{rpm}$, and the demagnetization is required at $10000 \mathrm{rpm}$; on the one hand, the axial length of the motor should consider the electricity magnetic properties, on the other hand, considering the rotor dynamic characteristics, the cross section of the motor is shown in Fig. 5.

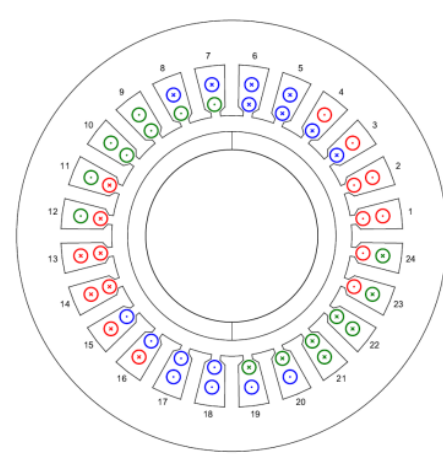

a) Rotor sectional view

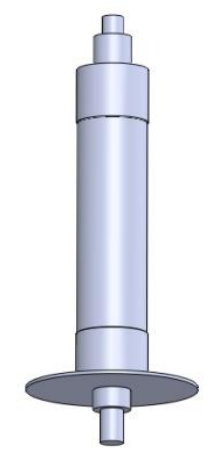

b) Rotor physical map
Fig. 5 Sketch of the rotor structure

Table 3

The main parameters of the motor

\begin{tabular}{|c|c|}
\hline Number of pole pairs & 1 \\
\hline Number of stator slots & 36 \\
\hline Phase & 3 \\
\hline Magnetic steel installation form & surface mount type \\
\hline \multicolumn{2}{|c|}{ Geometric parameter } \\
\hline Motor axial length & $110 \mathrm{~mm}$ \\
\hline Stator outer diameter & $95 \mathrm{~mm}$ \\
\hline Stator bore & $53 \mathrm{~mm}$ \\
\hline Outer diameter of rotor core & $38 \mathrm{~mm}$ \\
\hline Magnetic steel height & $4 \mathrm{~mm}$ \\
\hline Sheath height & $2 \mathrm{~mm}$ \\
\hline Polar coverage rate & 1 \\
\hline Tooth width & $3 \mathrm{~mm}$ \\
\hline Yoke height & $11.5 \mathrm{~mm}$ \\
\hline Groove opening height & $1 \mathrm{~mm}$ \\
\hline \multicolumn{2}{|c|}{ Material parameters } \\
\hline Stator & $\mathrm{m} 250-35 \mathrm{a}$ \\
\hline Rotor & stainless steel \\
\hline Magnetic steel & bms-22 \\
\hline Sheath & carbon fibre \\
\hline \multicolumn{2}{|c|}{ Winding parameters } \\
\hline Winding layer number & 2 \\
\hline Number of parallel branches & 2 \\
\hline Turns & 4 \\
\hline Pitch distance & 10 \\
\hline Number of parallel coils per turn & 28 \\
\hline Line diameter & $0.315 \mathrm{~mm}$ \\
\hline \multicolumn{2}{|c|}{ Other parameters } \\
\hline Magnetization direction & radial \\
\hline
\end{tabular}

Based on the above design results, Maxwell is used for finite element modeling (using periodic boundary conditions), the finite element model and grid are shown in Fig. 6.

In permanent magnet motors, the main magnetization methods are parallel magnetization, radial magnetization, halbach magnetization, etc., and parallel magnetization 
and radial magnetization are the most commonly used in permanent magnet magnetization [18]. However, the noload air gap magnetic field waveforms obtained by these two magnetization methods are different. Using the finite element software to establish a two-pole high-speed permanent magnet motor model, the flux density distribution of the two magnetization methods can be obtained as shown in Fig. 7.

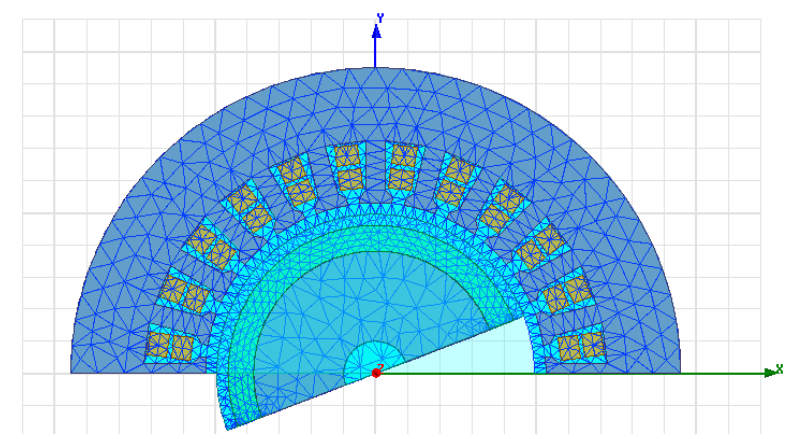

Fig. 6 Finite element model of the motor

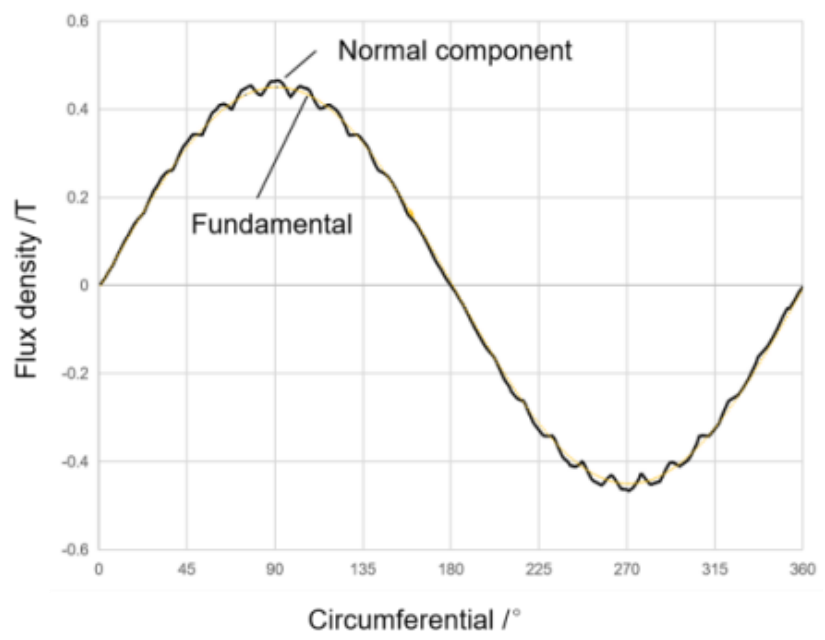

a) Flux density (parallel magnetization)

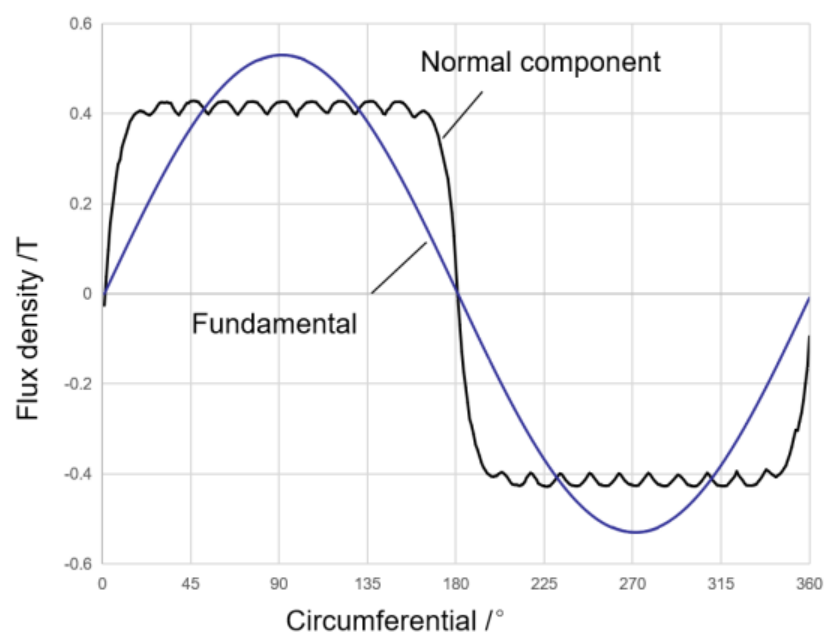

b) Flux density (radial magnetization)

Fig. 7 Flux density distribution of two magnetization methods

If parallel polarization is used, the flux density is basically sinusoidal (ignoring the effect of slotting), the fundamental component is $0.45 \mathrm{~T}$, but there will be a problem of low fundamental component at this time, it is not suitable to make full use of magnetic steel. When radial magnetization is used, the flux density distribution is similar to a square wave, so the amplitude of the fundamental wave can be further increased. In this design, the fundamental wave amplitude of the flux density is $0.53 \mathrm{~T}$, which is significantly better than the parallel magnetization method.

The rotor of PMSM is composed of 4 parts, they are motor shaft, rotor core, permanent magnet and non-magnetic sleeve, and the losses in the rotor are mainly mechanical losses and eddy current losses. Mechanical loss refers to air friction loss [19]. In general, the eddy current loss of the motor rotor is very small compared to the stator loss. However, when the eddy current loss occurs, the temperature of the permanent magnet will increase, and demagnetization will occur. In particular, irreversible demagnetization will occur.

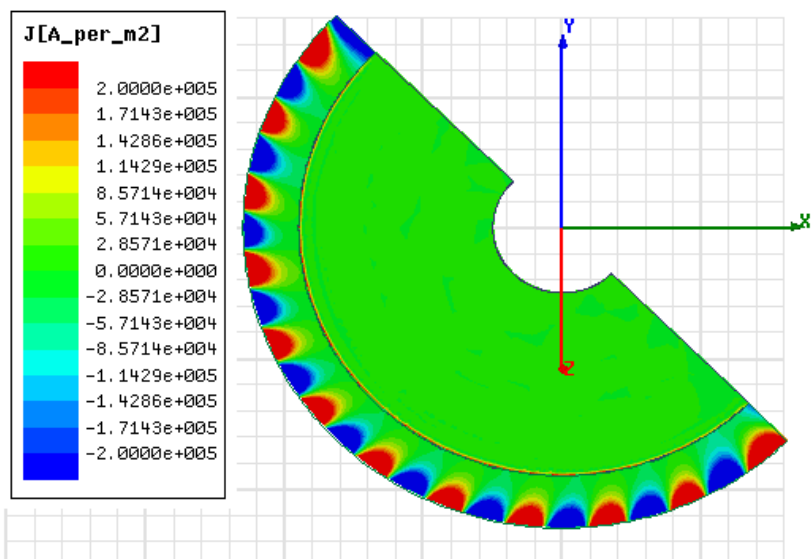

a) No load

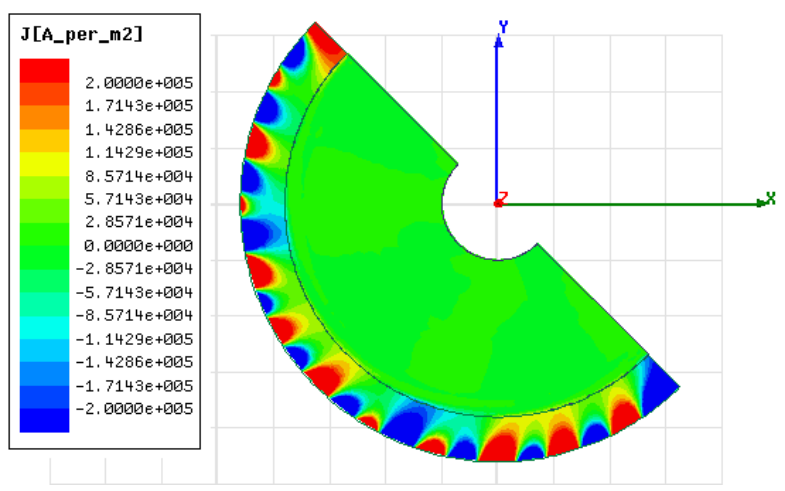

b) Load

Fig. 8 Finite element model of rotor loss

In the high-speed rotation state, both the magnetic steel and the solid rotor will induce eddy currents, causing additional rotor losses, excessive rotor temperature may cause serious effects such as irreversible loss of magnetic steel and damage to the sheath [20]. This part of the loss must be taken into consideration in the simulation, taking into account the three factors of rotor loss: 1) the magnetomotive force induced by the fundamental current of the stator side is not sinusoidal; 2) the current waveform of the stator side contains high-frequency harmonics; 3) the effect of stator slotting. The distribution of the magnetomotive force generated by the winding of this motor is quite high, and this part of the loss is small; considering the application of the filter, the harmonic component of the input current of most high-speed motors is low, or its harmonics are located at low 
frequencies. The rotor loss caused by the term is negligible. In summary, this design only considers the loss caused by the third term in the no-load state and the load state. The rotor loss model is shown in Fig. 8.

In order to make the finite element simulation as accurate as possible and reduce the calculation time, the permeability parameters of each material are taken as linear. At $100,000 \mathrm{rpm}$, the induced current density at no-load is shown in Fig. 8, a, the periodic distribution of eddy current and skin effect is clearly visible. Under 100,000 rpm no-load working conditions, the average cycle loss of the rotor is $2.3 \mathrm{~W}$, this loss is only caused by the third item in the above analysis. Instead of load state conditions, such as $10 \mathrm{~kW}$, the average cycle loss of the rotor at $10,000 \mathrm{rpm}$ is $2.7 \mathrm{~W}$, this part of the loss is caused by the first and third items above. The induced current density at this time is shown in Fig. 8, b, this can prove the correctness of the previous analysis of the three factors.

Consider the three operating points at speeds of $20,00080,000$ and 100,000 rpm, respectively, with a rated power of $10 \mathrm{~kW}$ and a maximum effective voltage between phases of $500 \mathrm{~V}$. The operating parameters at each operating point are shown in Table 4.

Table 4

Simulation operating parameters of each working point

\begin{tabular}{|c|c|c|c|}
\hline Operating point & $1 \#$ & $2 \#$ & $3 \#$ \\
\hline Power, kW & 10 & 10 & 10 \\
\hline Speed, rpm & 20000 & 80000 & 100000 \\
\hline Current, A $^{\circ}$ & 54.4 & 14.1 & 15.5 \\
\hline Current advance angle, $^{\circ}$ & 0 & 0 & 43.2 \\
\hline Current density, a / mm $^{2}$ & 12.5 & 3.2 & 3.6 \\
\hline Voltage, V $^{\text {Copper Loss, W }}$ & 119 & 432 & 500 \\
\hline Iron Loss, W & 419 & 28 & 34 \\
\hline Rotor Loss, W & 0.82 & 2.08 & 2.68 \\
\hline Efficiency & $94.7 \%$ & $90.0 \%$ & $87.2 \%$ \\
\hline Power factor & 0.94 & 1.0 & 0.79 \\
\hline $\begin{array}{c}\text { Electromagnetic torque, } \\
\text { nm }\end{array}$ & 4.8 & 1.24 & 1.0 \\
\hline Torque ripple, nm & 0.12 & 0.058 & 0.061 \\
\hline Torque ripple ratio & $2.5 \%$ & $4.7 \%$ & $6.1 \%$ \\
\hline
\end{tabular}

\section{Centrifugal compressor test}

According to the calculation results of the parameters, the CNC machine tool was used to manufacture and assemble the components, and the aerodynamic performance of the air compressor was tested and verified. The surface quality of the impeller, gas foil bearing, and rotor has a great influence on the aerodynamic performance, which directly affects the accuracy of the test results. The surface roughness and geometric tolerance of the key components such as the impeller channel are strictly controlled during the design and processing.

The centrifugal air compressor test bench needs to be able to easily test the working performance of the air compressor under different working conditions and record the corresponding test data for subsequent analysis. According to the test requirements and the characteristics of the centrifugal air compressor, the test bench pipeline is designed as shown in Fig. 9.

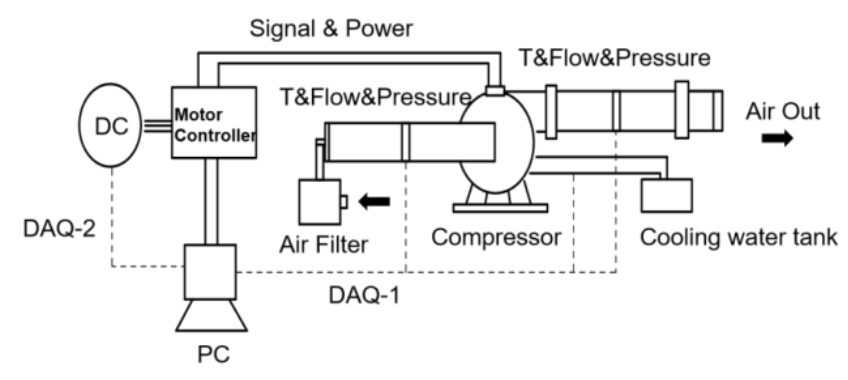

Fig. 9 Test bench of centrifugal air compressor

The experimental bench realized the air circulation circuit and water circulation circuit of the air compressor and expander and installed corresponding sensors and measuring instruments on each circuit to obtain the required test parameters. The flow was carried out through the pressure control valve at the outlet of the discharge pipe [21]. After the air in the atmospheric environment is processed by the muffler and filter, it enters the entrance of the test centrifugal air compressor, and the test centrifugal air compressor compresses the air to work and discharges it. Temperature sensors and pressure sensors are installed on the inlet and outlet pipes to measure the physical parameter changes before and after the air passes through the air compressor. Temperature sensors and air compressors are installed on the inlet and outlet pipes of the cooling water pipeline. The input power and speed information are obtained through the motor controller. The test bench is built with aluminium alloy profiles, including the main bench and the air compressor placement platform.

Fig. 10, a shows the relationship between the efficiency and mass flow at different speeds in the range of 20,000 to $100,000 \mathrm{rpm}$. The optimal flow rate and maximum efficiency are a function of the speed, and the efficiency curve varies with the speed. Under certain operating speed conditions, there is a very close relationship between pressure changes and flow changes. The left area of the characteristic curve is the surge area. When the rotation speed is $20,000 \mathrm{rpm}$, the maximum efficiency point is at the flow rate of $20 \mathrm{~g} / \mathrm{s}$. When the rotation speed is $100,000 \mathrm{rpm}$, the maximum efficiency point is at the flow rate of $50 \mathrm{~g} / \mathrm{s}$. Running at higher speeds will have higher efficiency, especially for larger flows, at a certain speed, if the flow exceeds the optimal value, the efficiency will decrease with the increase of the flow, and this phenomenon will be more obvious when the speed is lower. For the given flow rate in the actual situation, the best performance of the air compressor can be achieved by adjusting the speed.

Fig. 10, b shows the relationship between the pressure ratio and the flow rate at different speeds $(20,000$ to $100,000 \mathrm{rpm}$ ), the outlet pressure is a function of flow rate and speed. The required outlet pressure can be achieved by adjusting the flow rate or speed, the influence of the speed on the outlet pressure is much greater than that of the flow rate, therefore, adjusting the flow rate is preferred to achieve fine adjustment of the outlet pressure [22]. At a constant speed, as the flow rate decreases, the gradient of the pressure ratio-flow curve gradually changes from steep to gentle, and the operating point where the gradient changes from negative to positive is defined as the mild surge point. After a slight surge occurs, continue to reduce the flow rate, the pressure ratio is almost unchanged or even decreased until a deep surge occurs. 


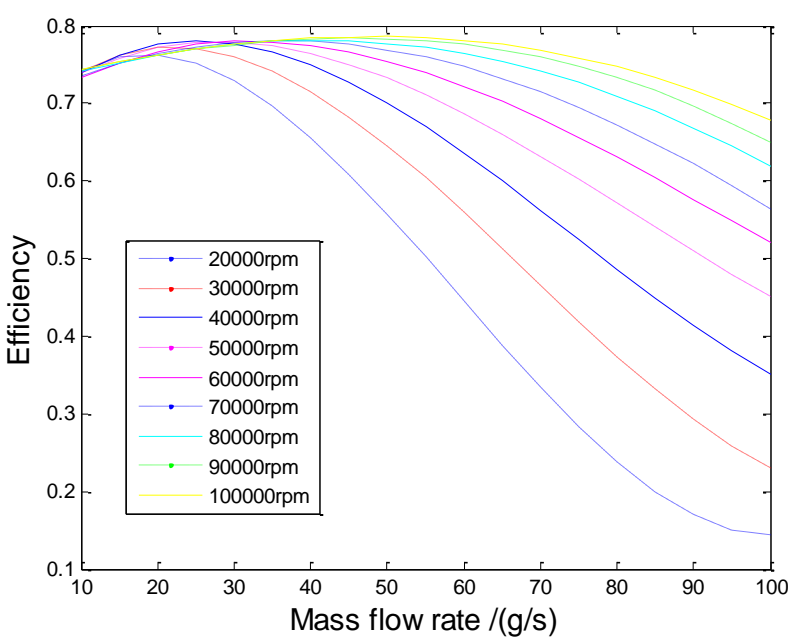

a) Efficiency-flow relationship

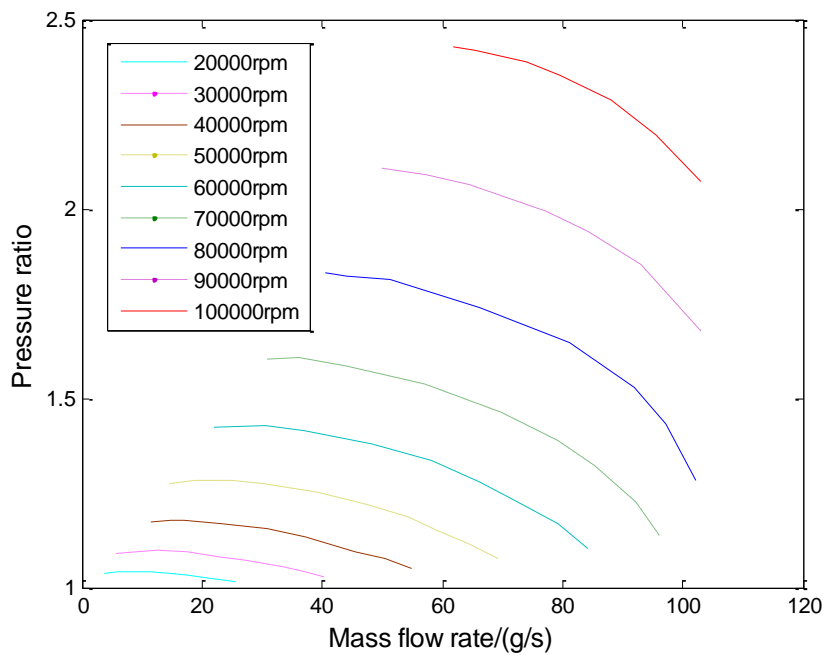

b) Pressure ratio-flow relationship

Fig. 10 Relationship between efficiency, pressure ratio and flow

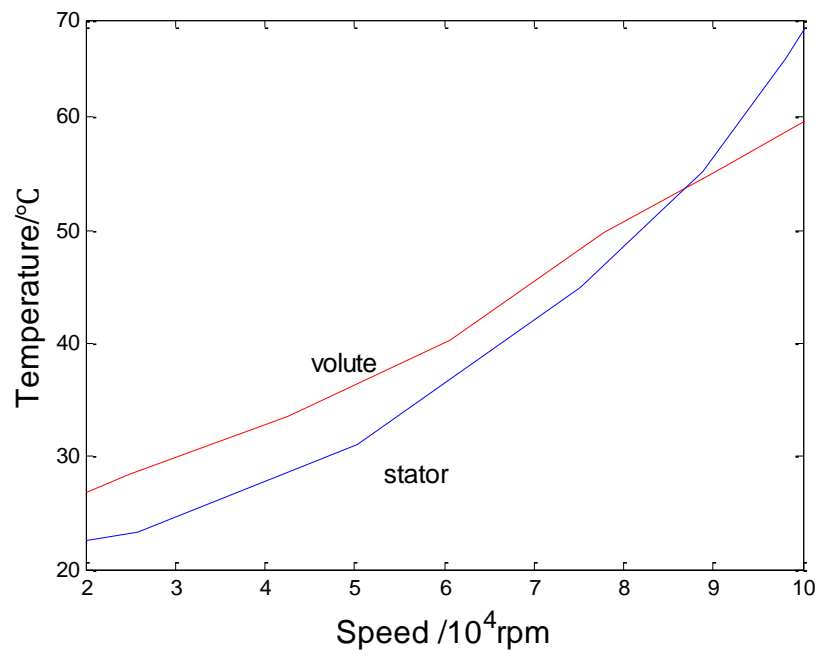

Fig. 11 Temperature of air compressor volute and stator

When the centrifugal air compressor is working, the compressed gas and the motor are the main heat sources. In order to improve heat dissipation, the cooling water channel and the air-cooling pipe are designed on the air compressor shell during structural design. The cooling water channel is mainly to take away the heat of the stator and the shell, and the air-cooling channel is mainly for cooling the gas foil bearing and the volute [23]. By installing temperature sensors on the volute and the stator, the law of the internal temperature changing with the rotation speed is measured, and the experimental environment temperature is $25^{\circ} \mathrm{C}$. As shown in Fig. 11, it can be seen that the temperature of the volute and the stator both increase with the increase of the speed, the temperature of the volute in the early stage is higher than the temperature of the stator, but the acceleration of the stator temperature rise is large. The stator copper wire winding and eddy current loss are relatively large, but the temperature of both is not higher than $70^{\circ} \mathrm{C}$, which is within a reasonable range.

Compared with traditional internal combustion engine vehicles, fuel cell vehicles have no obvious advantages in overall sound pressure level, and the sound quality is poor. Further analysis shows that the noise source of fuel cell vehicles mainly comes from the aerodynamic noise generated by the air compressor in the air auxiliary system. In actual operation, the outlet of the centrifugal compressor enters the fuel cell stack through the pipeline through the humidifier, and most of the aerodynamic noise is directly radiated outward from the inlet. The fan impeller and the drive motor are the main components of the centrifugal fan, and most of the noise is generated by these two parts.

The sound source information can be obtained from the calculation of the three-dimensional unsteady flow field. The FW-H method is used to calculate the aerodynamic noise of the compressor, including the sound source caused by the change in surface velocity, that is, the monopole sound source; the sound source caused by the surface pulsating pressure, that is, the dipole sound source; the sound source caused by the momentary strain applied to the fluid, that is, the quadrupole sound source. Among them, the dipole sound source plays a leading role in the aerodynamic noise of the centrifugal compressor. Therefore, in the Fluent simulation, the fixed dipole source of the volute wall surface and the dipole source of the blade wall motion are selected as the sound source to calculate the radiated sound field of the centrifugal compressor. According to GB/T2888-2008 "Measuring Methods of Fan and Roots Blower Noise", the noise monitoring points are arranged, and the sound power level of the whole machine is:

$$
\begin{aligned}
& L_{W A}=\bar{L}_{A}+10 \lg \left(\frac{S}{S_{0}}\right) \\
& S=2 \pi r^{2} \\
& S_{0}=1 \\
& \bar{L}_{A}=10 \lg \left(10^{0.1 L_{1}}+10^{0.1 L_{2}}+\ldots+10^{0.1 L_{n}}\right)-10 \lg ^{n},
\end{aligned}
$$

where: $L_{W A}$ is the sound power level of the whole machine, $\mathrm{dB}(\mathrm{A}) ; S$ is the transmission area, $\mathrm{m}^{2} ; S_{0}$ is the standard area, $\mathrm{m}^{2} ; \bar{L}_{A}$ is the average sound pressure level, $\mathrm{dB}(\mathrm{A}) ; L_{1}$, $L_{2}, \ldots, L_{n}$ is the sound pressure level measured by different noise measurement points, $\mathrm{dB}(\mathrm{A}) ; n$ is the number of noise measurement points.

This test mainly analyzes the noise characteristics of the centrifugal fan under test. It is necessary to exclude the test background noise and other interference noise. The test site is selected as a semi-anechoic room to ensure the 
accuracy of the test results. In this paper, the noise under different working conditions was tested, 14 microphones were arranged, and the microphone positions were in the center of 6 area units and 8 corners, respectively. The equipment layout of noise test is shown in the Fig. 12, the noise test adopts the G.R.A.S.40PH1/2 microphone, and the test data collection and analysis adopts the LMS Test. Lab system.

The steady state test includes $20000-100000 \mathrm{rpm}$, interval $10000 \mathrm{rpm}$, a total of 9 steady state speeds, adjust the compressor outlet valve, make the compressor run stably at the specific operating point at this speed, the steady state working conditions collect the compressor stable operation Noise, flow, pressure and other performance parameter signals within $20 \mathrm{~s}$.
It can be clearly seen from Table 5 that as the speed increases, the sound power level gradually increases, but still does not exceed $70 \mathrm{~dB}(\mathrm{~A})$, and subsequent noise reduction measures can be used to ensure that the noise added to the interior of the car no more than $40 \mathrm{~dB}(\mathrm{~A})$, to ensure a better ride experience. In the follow-up research, the sources of noise can be further analyzed through theory and experiments, such as fan noise: rotating noise, eddy current noise, intake noise, motor noise: excitation current noise, electromagnetic noise, rotational unbalance noise, and housing inherent noise, etc. The noise reduction is carried out from the aspects of optimization of the housing structure of the drive motor, installation of a muffler at the entrance, and optimization of vibration performance.

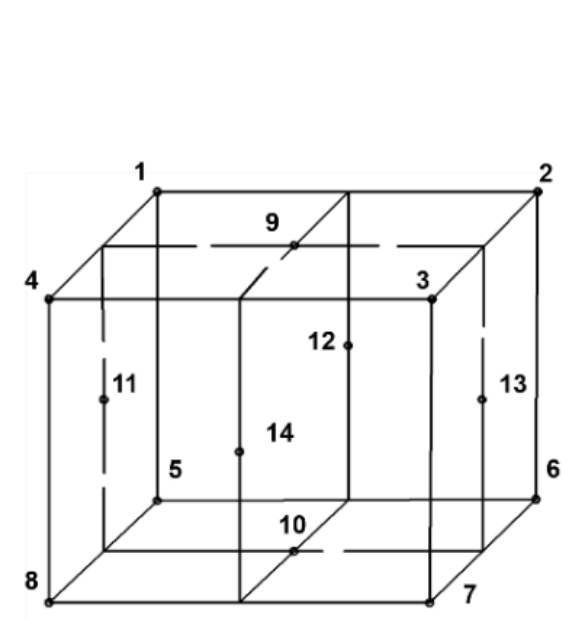

a) Microphone arrangement

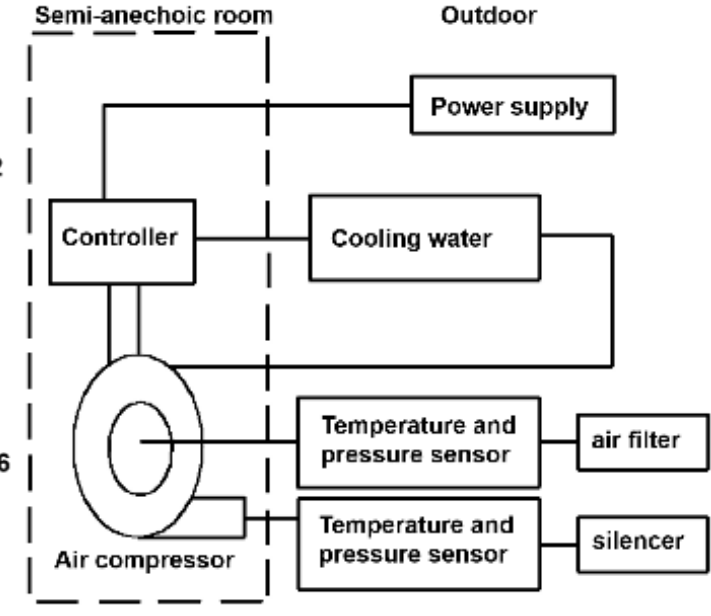

b) Air compressor test layout

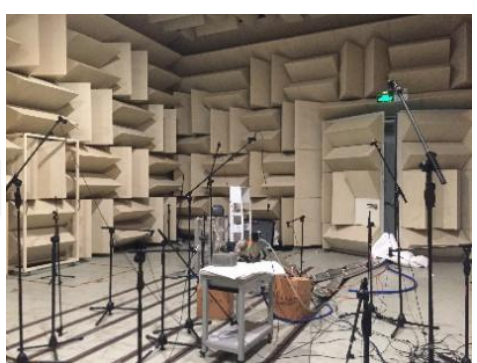

c) Semi-anechoic room test site

Fig. 12 Noise test layout and test site

Table 5

Sound power level noise test results

\begin{tabular}{|c|c|c|c|c|c|c|c|c|c|}
\hline \multirow{2}{*}{ No. } & Speed & Opening & Power & Current & Voltage & Flow & $\begin{array}{c}\text { Pressure } \\
\text { ratio }\end{array}$ & $\begin{array}{c}\text { Background } \\
\text { noise }\end{array}$ & $\begin{array}{c}\text { Sound power } \\
\text { level noise }\end{array}$ \\
\cline { 2 - 9 } & $\mathrm{rpm}$ & $\%$ & $\mathrm{~kW}$ & $\mathrm{~A}$ & $\mathrm{~V}$ & $\mathrm{~g} / \mathrm{s}$ & Out/In & $\mathrm{dB}, \mathrm{A}$ & $\mathrm{dB}, \mathrm{A}$ \\
\hline 1 & 20000 & 50 & 0.25 & 0.5 & 500 & 22.2 & 1.03 & $<20$ & 44.5 \\
\hline 2 & 30000 & 50 & 0.6 & 1.2 & 500 & 32.7 & 1.05 & $<20$ & 50.1 \\
\hline 3 & 40000 & 50 & 1.05 & 2.1 & 500 & 44.3 & 1.11 & $<20$ & 53.2 \\
\hline 4 & 50000 & 50 & 1.9 & 3.8 & 500 & 56.2 & 1.13 & $<20$ & 57.9 \\
\hline 5 & 60000 & 50 & 3.1 & 6.2 & 500 & 66.9 & 1.21 & $<20$ & 61.1 \\
\hline 6 & 70000 & 50 & 4.7 & 9.4 & 500 & 801 & 1.24 & $<20$ & 63.5 \\
\hline 7 & 80000 & 50 & 6.85 & 13.7 & 500 & 93.7 & 1.31 & $<20$ & 56.1 \\
\hline 8 & 90000 & 50 & 9.4 & 18.8 & 500 & 103.2 & 1.34 & $<20$ & 63.6 \\
\hline 9 & 100000 & 50 & 12.1 & 24.2 & 500 & 114.1 & 1.45 & $<20$ & 66.3 \\
\hline
\end{tabular}

\section{Conclusion}

In this paper, a centrifugal air compressor driven by an gas foil bearing support and driven by a permanent magnet synchronous motor has been developed to achieve stable operation. In the study of key technologies such as the mechanical structure of air compressors, bearings, and motors, the following conclusions were obtained.

The air compressor uses a high-speed permanent magnet synchronous motor as the driving device, which realizes the organic fusion of the gas foil bearing and the permanent magnet motor. Through the prototype test, the mass flow rate of the air compressor at a speed of $100,000 \mathrm{rpm}$ is
$65 \mathrm{~g} / \mathrm{s}$, the pressure ratio is 2.3 , the motor efficiency is $75 \%$, which can meet the requirements of $60 \mathrm{~kW}$ fuel cell vehicles. The compressor has a wide and flat characteristic. The characteristics of centrifugal compressors equipped with gas foil bearings were studied to verify the feasibility of their application in FCEV. The compressor plays an important role in the fuel cell system. The compression of air makes FCEV have higher efficiency and power density. The gas foil bearing brings a more obvious advantage to the compressor, and the speed of the compressor greatly exceeds the rolling bearing. The higher design speed can ensure that the compressor has higher efficiency under the conditions of 
low flow and high pressure. The structure design and performance of the high-speed motor used in the compressor were studied and the electrical performance indexes of the developed motor meet the requirements of stator core loss and rotor eddy current loss. According to the functional requirements, the motor structure is determined as stator slot, rotor table. For the stick-type permanent magnet motor, Ansoft is used for modelling and simulation analysis of the motor. Comparing the electrical performance changes of different magnetization methods, radial magnetization is obviously superior to parallel magnetization. An experimental study has been conducted on the noise characteristics of the air compressor. The results show that the system has good noise performance, which can ensure that the interior riding space has a better experience during the driving of the vehicle.

\section{Acknowledgement}

The authors acknowledge the project"Hebei Graduate Innovation Fund", No. CXZZBS2017136 financed by the Hebei Provincial Department of Education, China. "Key R \& D project of Hebei Province”, No. 20312203D, China.

\section{References}

1. Gee, M. K.; Garbak, J.; Sutton, B. 2003. Cost and Performance Enhancements for a PEM Fuel Cell System. [Online]. Available from Internet: https://www.hydrogen.energy.gov/pdfs/progress04/ivh5_gee.pdf.

2. Walton, J. F.; Tomaszewski, M. J.; Heshmat, C. A. 2006. On the Development of an Oil-Free Electric Turbocharger for Fuel Cells, 51st ASME Turbo Expo 5: 395-400. http://dx.doi.org/10.1115/GT2006-90796.

3. Ha, K. K.; Jeong, T. B.; Kang, S. H.; Kim, H. J.; Won, K. M.; Park, C. Y.; Jung, W. Y.; Cho, K. S. 2013. Experimental investigation on aero-acoustic characteristics of a centrifugal compressor for the fuel-cell vehicle, Journal of Mechanical Science \& Technology 27(11): 3287-3297. http://dx.doi.org/10.1007/s12206-013-0851-y.

4. Sugawara, T.; Kanazawa, T.; Imai, N.; Tachibana, Y. 2017. Development of motorized turbo compressor for clarity fuel cell, SAE Technical Paper 2017: 1-7. https://doi.org/10.4271/2017-01-1187.

5. Hong, D. K.; Woo, B. C.; Lee, J. Y.; Koo, D. H. 2012. Ultra high speed motor supported by air foil bearings for air blower cooling fuel cells, IEEE Transactions on Magnetics 48(2): 871-874.

https://doi.org/10.1109/TMAG.2011.2174209.

6. Raminosoa, T.; Blunier, B.; Fodorean, D.; Miraoui, A. 2010. Design and optimization of a switched reluctance motor driving a compressor for a pem fuel-cell system for automotive applications, IEEE Transactions on Industrial Electronics 57(9): 2988-2997. https://doi.org/10.1109/TIE.2010.2041133.

7. Munz, S.; Schier, M.; Schmalzl, H. P.; Bertolini, T. 2008. eBooster design and performance of a innovative electrically driven charging system [Online]. Available from Internet: http://www.turbos.bwauto.com/files/library/bwtslibrary\%20138\%20325.pdf.

8. Gerada, D.; Mebarki, A.; Brown, N. L.; Bradley, K.
J.; Gerada, C. 2011. Design aspects of high-speed highpower-density laminated-rotor induction machines, IEEE Transactions on Industrial Electronics 58(9): 4039-4047.

http://dx.doi.org/10.1109/TIE.2010.2098364.

9. Wan, Y.; Guan, J.; Xu, S. 2016. Improved empirical parameters design method for centrifugal compressor in PEM fuel cell vehicle application, International Journal of Hydrogen Energy 42(8): 590-605. https://doi.org/10.1016/j.ijhydene.2016.08.162.

10. Park, J.; Sim, K. 2018. A feasibility study of controllable gas foil bearings with piezoelectric materials via rotordynamic model predictions, Journal of Engineering for Gas Turbines and Power 141(2): 021-027. http://dx.doi.org/10.1115/1.4041384.

11. Zywica, G.; Baginski, P. 2019. Investigation of gas foil bearings with an adaptive and non-linear structure, Acta Mechanica et Automatica 13(1): 5-10. http://dx.doi.org/10.2478/ama-2019-0001.

12. Feng, K.; Shigehiko, K. 2010. Parametric studies on static performance and nonlinear instability of bumptype foil bearing, Journal of system design and dynamics 4(6): 871-883. http://dx.doi.org/10.1299/jsdd.4.871.

13. Lee, D. H.; Kim, Y. C.; Kim, K. W. 2008. The static performance analysis of foil journal bearings considering three-dimensional shape of the foil structure, Journal of Tribology 130(3): 031102. http://dx.doi.org/10.1115/1.2913538.

14. Ravikumar, R. N.; Rathanraj, K. J.; Kumar, V. A. 2016. Comparative experimental analysis of load carrying capability of air foil thrust bearing for different configuration of foil assembly, Procedia Technology 25: 1096-1105. http://dx.doi.org/10.1016/j.protcy.2016.08.215.

15. Park, D. J.; Kim, C. H.; Jang, G. H.; Lee, Y. B. 2008. Theoretical considerations of static and dynamic characteristics of air foil thrust bearing with tilt and slip flow, Tribology International 41(4): 282-295. http://dx.doi.org/10.1016/j.triboint.2007.08.001.

16. Lehn, A.; Mahner, M.; Schweizer, B. 2018. A thermoelasto-hydrodynamic model for air foil thrust bearings including self-induced convective cooling of the rotor disk and thermal runaway, Tribology International 119: 281-298. http://dx.doi.org/10.1016/j.triboint.2017.08.015.

17. Bottauscio, O.; Casaro, F.; Chiampi, M.; Giors, S.; Maccarrone, C.; Zucca, M. 2006. High-speed drag-cup induction motors for turbo-molecular pump applications, IEEE Transactions on Magnetics 42(10): 34493451 . http://dx.doi.org/10.1109/TMAG.2006.879446.

18. Mekhiche, M.; Nichols, S.; Kirtley, J. L.; Yong, J.; Boudreau, D.; Jodoin, R. 2001. High-speed, highpower density PMSM drive for fuel cell powered HEV application, IEEE International Electric Machines and Drives Conference 2001: 658-663. http://dx.doi.org/10.1109/IEMDC.2001.939384.

19. Dubas, F.; Espanet, C.; Miraoui, A. 2005. Design of a high-speed permanent magnet motor for the drive of a fuel cell aircompressor, IEEE Vehicle Power and Propulsion Conference 2005: 603-610. http://dx.doi.org/10.1109/VPPC.2005.1554621.

20. El-Shahata, A.; Hunter, A.; Rahman, M.; Wu, Y. 
2019. Ultra-high speed switched reluctance motor-generator for turbocharger applications, Energy Procedia 162: 359-368.

https://doi.org/10.1016/j.egypro.2019.04.037.

21. Ma, S.; Afzal, A.; Kim, K. 2018. Optimization of ring cavity in a centrifugal compressor based on comparative analysis of optimization algorithms, Applied Thermal Engineering 138: 633-647.

http://dx.doi.org/10.1016/j.applthermaleng.2018.04.094.

22. Zhao, D.; Dou, M.; Blunier, B.; Miraoui, A. 2012. Control of an ultra-high speed centrifugal compressor for the air management of fuel cell systems, IEEE Transactions on Industry Applications 50(3): 2225-2234. http://dx.doi.org/10.1109/TIA.2013.2282838.

23. Ju, Y.P.; Zhang, C.H. 2014. Design optimization and experimental study of tandem impeller for centrifugal compressor, Journal of Propulsion and Power 30(6): 1390-1501.

http://dx.doi.org/10.2514/1.B34933.
W. Li, G. Feng

\section{DESIGN AND EXPERIMENTAL STUDY OF CENTRIFUGAL COMPRESSOR IN FUEL CELL VEHICLE}

S u m m a r y

A high-speed centrifugal air compressor structure supported by aerodynamic pressure bearings and driven by a permanent magnet synchronous motor was proposed. The integration of air lubrication and permanent magnet synchronous motor is realized, which meets the fuel cell system's requirements for oil-free and efficient. Based on the analysis of the principle of aerodynamic pressure bearing and high-speed motor, the parameters of each component were designed, and the prototype of the air compressor was developed. When working at $10 \times 104 \mathrm{rpm}$, it can provide compressed air with a maximum pressure ratio of 2.3 , and the overall efficiency is close to $80 \%$, which achieves highspeed and stable operation, has higher efficiency and wider and flat working characteristics. Finally, the feasibility of the design was verified by bench test.

Keywords: centrifugal air compressor, gas bearing, permanent magnet synchronous motor, fuel cell systems.

Received April 17, 2020

Accepted February 17, 2021 